\title{
TRAJETÓRIAS E EXPERIÊNCIAS ESCOLARES DE ESTUDANTES COTISTAS NEGROS/AS DA UNILAB: IDENTIDADES, CURRÍCULO E PRÁTICAS PEDAGÓGICAS
}

\author{
TRAJECTORIES AND SCHOOL EXPERIENCES OF BLACK QUOTA STUDENTS \\ OF UNILAB: IDENTITIES, CURRICULUM AND PEDAGOGICAL PRACTICES
}

\author{
Francisco Érick de Oliveira ${ }^{1}$ \\ 1 Doutorando em Sociologia, UFPB - Bolsista CAPES. Mestre em Humanidades, 2019; licenciado em \\ Sociologia, 2018; bacharel em Humanidades, 2014 - Universidade da Integração Internacional da \\ Lusofonia Afro-brasileira. E-mail: erick.oliveira2@outlook.com
}

ARTICLE INFO

Article history:

Received 2019-11-23

Accepted 2020-01-03

Available online 2020-02-20
Palavras-chave: Sucesso escolar. Discriminação étnicoracial. Identidades negras. Currículo. Práticas pedagógicas. Keywords: School success. Ethnic-racial discrimination. Black identities. Curriculum. Pedagogical practices.

RESUMO. Os objetos de estudo deste trabalho estão situados entre um debate mais amplo e sempre urgente, com ênfase no contexto brasileiro, entre classe, raça e/ou etnia. A problematização construída é um recorte de questões da minha pesquisa de mestrado que se debruçou sobre o sucesso escolar de seis estudantes negros/as, cotistas, das camadas populares e de cursos de graduação da UNILAB, no Ceará, através de uma metodologia disposicionalista. Por meio de trajetórias e narrativas (auto)biográficas, busquei reconstruir cenários de socialização de disposições de longevidade escolar a fim de compreender como se constituíram possibilidades de acesso ao ensino superior em condições socioeconômicas e culturais sociologicamente desfavoráveis. A questão étnico-racial é central em função do debate sobre a Política de Cotas e das identidades negras apresentadas pelo universo. Nesta oportunidade, porém, tomo-a por outro caminho, a fim de tencionar os limites de uma interpretação centrada apenas na camada social, quanto às condições objetivas de existência, considerando a importância dos marcadores étnico-raciais nas experiências escolares, especificamente, e no desenvolvimento de capitais, disposições e identidades. Nos cenários de socialização de disposições de longevidade encontrei configurações familiares com racionalização da vida em torno do campo escolar, alinhados com atividades extraescolares que intensificaram a formação de habitus coerentes; e envolvimentos em programas, projetos e políticas públicas.

\begin{abstract}
The study objects of this work are situated between a broad and always urgent debate, with emphasis on the Brazilian context, between class, race and/or ethnicity. The problematization built is a clipping of questions from my master's research that focused on the school success of six black quota students, from the lower classes and undergraduate courses of UNILAB, in Ceará, through a dispositionalist methodology. Through (self) biographical trajectories and narratives, I sought to reconstruct socialization scenarios of school longevity dispositions in order to understand how possibilities of access to higher education were constituted in socioeconomic and culturally unfavorable conditions. The ethnic-racial issue is central to the debate on Quota Policy and the black identities presented by the universe. On this occasion, however, I take it the other way, in order to stress the limits of an interpretation centered only on the social layer, as to the objective conditions of existence, considering the importance of ethnic-racial markers in school experiences, specifically, and in capital development, arrangements and identities. In the longevity dispositions socialization scenarios, I found family configurations rationalization of life around the school field, aligned with extra-school activities that intensified the formations of coherent habitus; and involvement in programs, projects and public policies.
\end{abstract}




\section{Introdução}

Neste trabalho, abordo algumas temáticas e problemas da minha pesquisa de mestrado, realizada entre 2017 e 2019, no Mestrado Interdisciplinar em Humanidades da Universidade da Integração Internacional da Lusofonia Afro-brasileira (UNILAB). Tenciono questões referentes ao preconceito e à discriminação racial na escola e às experiências de formação identitária, atentando para as ausências de mediação pedagógica e de gestão quanto às formas de racismo, em suas diversas faces interconectas, e caminhos possíveis para práticas antirracistas.

Busquei reconstruir as disposições sociais (LAHIRE, 2002; 2004) de seis estudantes negros/as cotistas dos cursos de graduação da UNILAB - CE, oriundos/as das camadas populares (família pouco escolarizada; trabalhos e ocupações manuais e/ou informais; e renda familiar entre um e dois salários mínimos), afim de compreender como e em quais espaços foram socializadas condições de longevidade escolar (conceito utilizado como semelhante ao de sucesso escolar, mas incorporando uma crítica quanto à efetividade desse sucesso; VIANA, 1998), considerando-se toda uma bibliografia sociológica que projeta nas camadas populares menores possibilidades de escolarização duradoura em função da posse insuficiente de capitais culturais, econômicos e sociais ${ }^{1}$.

A interlocução com os/as agentes se deu via questionário semiestruturado e entrevistas individuais e em profundidade. Elaboro este recorte problemático com o objetivo de, a partir das trajetórias e narrativas (auto)biográficas dos/as estudantes, primeiro, visualizarmos em que circunstâncias (entre as coisas ditas e não ditas) os preconceitos, discriminações raciais e relações de mestiçagem e branqueamento proliferam e como enfrentá-las na base curricular, na gestão escolar e nas práticas pedagógicas. Segundo, para reiterarmos a necessidade da formação docente continuada, atualizada e crítica em vistas do amadurecimento e aprofundamento das questões étnico-raciais na Educação.

Dentre os cenários de socialização de disposições de longevidade escolar, encontrei um conjunto de articulações familiares (com maior protagonismo das mães) que racionalizam a vida no lar e em torno dele em função das rotinas e benefícios da vida escolar; ambientes extraescolares que facilitaram a experiência com valores minimamente coerentes com os da escola; e programas e projetos públicos de Educação integral e reserva de vagas por critérios de renda e autodeclaração étnico-racial. Apesar destas combinações de espaços, experiências e sujeitos, os preconceitos e discriminações

\footnotetext{
${ }^{1}$ Esta pesquisa foi fomentada pela Fundação Cearense de Apoio ao Desenvolvimento Científico e Tecnológico FUNCAP e orientada pelo Professor Carlos Henrique Lopes Pinheiro. Na íntegra, foram trabalhados 7 casos. Porém, uma das interlocutoras participou apenas da fase dos questionários. Como estou refletindo questões das narrativas (auto)biográficas coletadas em entrevistas, logo, conto como sendo apenas 6 participantes.
} 
(individuais-institucionais-estruturais) mantiveram-se como barreira na dinâmica das identidades negras, seja pela mestiçagem, o branqueamento ou a ausência de conteúdos curriculares e extracurriculares da história e cultura africana e afro-brasileira. Por isso, o recorte centrado na esfera escolar.

É importante que se dialogue sobre isso, correlacionando que somente a posse de capitais (numa perspectiva de condições de classe e camada social) não garante o tráfego bem-sucedido dos indivíduos no campo da Educação, visto que os marcadores étnicos e/ou raciais são potentes e potencializadores, principalmente, no contexto brasileiro - um dos últimos países da América Latina a abolir a escravidão, ainda profundamente atravessado por desigualdades socioeconômicas que atingem, em sua maioria, as populações negras. No primeiro tópico, ensaio algumas ideias sobre a relação indivíduo-sociedade, introduzindo questões sobre a centralidade da subjetividade na construção de sentidos e significados (WEBER, 2002) quanto à experiência social. No segundo, apresento alguns argumentos sobre a centralidade dessa experiência com base nos dados empíricos que coletei. No terceiro, posiciono-me em relação à possibilidade de uma outra experiência escolar, referente ao conjunto de Leis e Diretrizes para uma Educação das relações étnico-raciais.

\section{Entre o subjetivo e o objetivo}

As articulações teóricas que ensaio aqui são muito caras à Sociologia, pois, dentre tantos temas e temáticas desenvolvidas em nosso campo, o debate em torno da relação indivíduo-sociedade é um dos mais recorrentes. Não o explorarei com tanta regressão, sintetizando Durkheim e a primazia dada à sociedade em relação ao indivíduo, ou Weber, em razão oposta, por exemplo. Partirei, especificamente, da perspectiva bourdiesiana e a centralidade do conceito de habitus (BOURDIEU, 2011; 2013), ilustrando a estrutura metodológica que guiou a minha pesquisa. Escolhi este caminho, tanto para a pesquisa quanto para a organização deste trabalho, pois tomo o debate entre agência e estrutura como centro teórico-metodológico de composição dos meus problemas de pesquisa e da maneira como enxergo e reconstruo a realidade social analiticamente. Incorporar os marcadores étnico-raciais, neste debate, significa problematizar as tradições canônicas com outras variáveis para além da mais proeminente, a classe social. É nesta esteira que tenho, portanto, conduzido minha produção pós-mestrado, por exemplo. Portanto, a discussão que segue registra minhas inferências quanto à questão da socialização como sendo composta pelos marcadores de classe e, tão importantes quanto, pelos marcadores étnico-raciais (e que não exclui os demais que aparecerem empiricamente, como gênero, geração, sexualidades, etc.). 
O habitus bourdiesiano é uma ferramenta analítica muito competente que promete sistematizar a lógica de constituição simultânea, porque dialética (ainda que eu mantenha minhas ressalvas quanto aos determinismos), da sociedade e do indivíduo (estrutura e agência), com o intento de compreender os princípios da prática e das representações, com base nos condicionamentos das condições de existência. Para o autor, o habitus pode ser definido como:

(...) sistemas de disposições duráveis e transponíveis, estruturas estruturadas predispostas a funcionar como estruturas estruturantes, ou seja como princípios gerados e organizadores de práticas e de representações que podem ser objetivamente adaptadas ao seu objetivo sem supor a intenção consciente de fins e o domínio expresso das operações necessárias para alcançá-los, objetivamente "reguladas" e "regulares" sem em nada ser o produto da obediência a algumas regras e, sendo tudo isso, coletivamente orquestrada sem ser o produto da ação de um maestro (BOURDIEU, 2011, p. 87).

Estas disposições (que compõem sistemas, logo, pressupondo certa coerência) são formas de perceber, sentir e pensar; habilidades, inclinações e atitudes interiorizadas pelos indivíduos e produzidas pelas condições objetivas de existência. Em sua visão, para serem apreciáveis, elas precisam ser duráveis, consistentes (e insistentes), pois estariam ancoradas em um passado gerador objetivamente sedimentado no agente. Elas também possuem um caráter de disponibilidade à transmissão (afinal, são adquiridas). Por serem um passado incorporado e sedimentado com maior durabilidade, elas são estruturas estruturadas pelas condições de existência e com inclinação a funcionarem como estruturas estruturantes. Elas são construções aptas a construir, então.

A aplicação inicial do questionário semiestruturado ao universo empírico buscava mapear, minimamente, características das condições de existência socioeconômica e cultural do estudante e das estudantes e, assim, compreender superficialmente em quais camadas sociais, nos termos já definidos (escolarização, trabalho/ocupação e renda), eles se encontravam. Obtive uma média salarial que não superava dois salários mínimos, em um cenário de pais e mães pouco escolarizados/as, a maioria com ensino fundamental incompleto, e agricultores/as, basicamente. Em macroescala sociológica, este não é um cenário propício de longevidade escolar. Pelo contrário, constitui um problema interessante de ser investigado porque cria questões não apenas no campo teórico, mas no campo metodológico.

Acolhi a crítica de Lahire (2002) e aceitei o desafio quanto à unicidade deste princípio gerador conceituado por Bourdieu (2011), sinalizando a necessidade de se considerar princípios geradores, no plural; a problematização do estado de transponibilidade, passível de teste empírico e maior compreensão das formas de transmissão; e maior "flexibilização" da estrutura pelo contexto, pela própria ação, etc. Segui com o método de entrevistas individuais e em profundidade (LAHIRE, 2004), buscando reconstruir, em escala 
microssociológica, para além das condições socioeconômicas e culturais apresentadas acima, disposições de longevidade escolar.

A crítica me parece, portanto, potencial não "apenas" em termos da variedade de princípios geradores, pela pluralidade e heterogeneidade de espaços de socialização nos quais os agentes circulam, mas na própria consideração da experiência, do contexto, da subjetividade, na construção de capitais escolares. O habitus bourdiesiano não pressupõe maestro, nem intenção consciente, um problema bastante interessante desenvolvido em algumas de suas obras (BOURDIEU, 2011; 2016). Isto quer dizer, de maneira muito geral, que a síntese das relações produz determinadas estruturas estruturadas e estruturantes que se originam pelo "todo" e, ao mesmo tempo, não se ancoram em "ninguém" especificamente. O agente não guia a sua ação de modo interessado, pela consciência das condições objetivas que incorporou. Ele é imbuído de disposições que se formaram sem necessariamente terem sido conscientemente incorporadas e sem serem mobilizadas conscientemente para a prática.

Longe de questionar o "problema da consciência e não-consciência" que ele desenvolve, porque o considero muito coerente, acrescentei à interpretação das narrativas coletadas um caráter compreensivo, ou seja, de valorização dos sentidos e significados (WEBER, 2002) atribuídos aos elementos contidos nas relações sociais. Ao analisar estas narrativas (auto)biográficas, pude encontrar inúmeras variáveis objetivas, estruturadas e estruturantes dos capitais escolares, incorporados por cada agente e a agência de disposições. Contudo, além da valorização das condições de existência condicionantes destas disposições de longevidade, dei primazia às interpretações que cada agente construía ao longo da narrativa, registrando um conjunto de sentidos e significados importantes de serem organizados a fim de compreender como, inclusive, se produzem, transferem-se e incorporam-se disposições sociais.

Mesmo que estas disposições e capitais não sejam conscientemente conjurados em termos práticos, estes sentidos e significados atribuídos à experiência (ainda que bastante determinados pelo próprio passado feito habitus, em termos de possibilidades objetivas BOURDIEU, 2011; 2013) são potenciais na elaboração de uma relação menos contraditória com o campo escolar, facilitando o desenvolvimento de capitais não herdados. O que quero dizer, e por isso me centro apenas nas experiências escolares, é que os capitais que não foram herdados na família foram adquiridos, com maior ênfase, na escola. Ainda assim, um elemento se destaca como conflituoso: o preconceito/discriminação étnico-racial. É nesta abertura para com a "experiência" e seus significados que gostaria de problematizar os limites das interpretações centradas nas condições socioeconômicas e culturais quando há a presença do racismo e suas diversas faces interconectas. 


\section{A experiência escolar: capitais e identidades}

O recorte que elaboro com relação à variável escolar como espaço na socialização de disposições de longevidade só existe em termos analíticos. Na realidade social, as variáveis que encontrei na pesquisa estão intrinsecamente interligadas, formando relações e influências muito complexas. Ainda assim, objetivo refletir sobre as esferas da Educação e da escola como instituições mobilizadoras de disposições sociais e capitais que transformam as heranças familiares sociologicamente frágeis, mas que, ao mesmo tempo, agem no enfraquecimento e deslegitimação das identidades negras, criando contradições na experiência. Trabalharei com os sentidos e significados percebidos nas narrativas de Andressa, Bárbara, Débora, Fábia, José e Mariana (os nomes são fictícios).

Em todos os seis casos, a escola aparece como este centro portador e socializador de capitais culturais e disposições de longevidade fundamentais para a construção de condições necessárias à corrida dos méritos. Nos casos de Fábia e Débora, a escola é um fator "direto", pois ela assume a função própria de socialização de saberes; a escola é, para elas, um espaço desejado e de realização pessoal; por meio dela é possível planejar um "futuro diferente". Nos casos de Andressa, Bárbara e José, a escola também se apresenta como fator "direto", que desperta a curiosidade, aguça o desejo de aprender e de "ser mais", que estimula o desenvolvimento de habilidades, experiências e oportunidades, mas com profundo desconforto, seja pelo preconceito e discriminação raciais ou pelo bullying ${ }^{2}$, criadores de contradição e conflito. O caso de Mariana é de oposição completa. Sua relação com a escola (inclusive, com a Universidade, ainda que em menor grau) é de total desconforto, pelo sentido incorporado de incapacidade causado pelo excesso de cobrança e de obrigações.

Ao elencar alguns dos aspectos dessas relações com a escola, objetivo ilustrar o quanto o sentido atribuído ao ambiente escolar revela a legitimidade da variável na produção e transferência de capitais e disposições e, também, como é um recurso interessante na compreensão do passado incorporado, pois, como já destaquei anteriormente, estes sentidos não fogem completamente dos princípios geradores. Muito de outras variáveis de socialização são influentes na criação de conforto ou conflito com o ambiente escolar, logo, de validação ou invalidação deste espaço como mobilizador de "possibilidades de futuro".

\footnotetext{
2 Termo da língua inglesa que se refere às formas de intimidação, violência física e/ou psicológica sistemáticas, em atos de humilhação e/ou discriminação, com acentuados casos no ambiente escolar. Diferencia-se das brigas "comuns" quando se tornam rotineiras e determinados indivíduos ou grupos passam a ser perseguidos.
} 
No entanto, uma questão étnico-racial está explícita ou implicitamente ligada com os sentidos construídos na relação com a escola. Com exceção de Andressa, que autodeclarase como negra quilombola (não fez declaração de cor nem no questionário, nem na entrevista), e de José, que no questionário se declarou como pardo e na entrevista, influenciado pelos aprendizados teóricos da graduação, autodeclarou-se como negro (sem declaração de cor), todas as demais estudantes autodeclaram-se como pardas.

Andressa, Bárbara, José e Mariana sofreram preconceito e discriminação étnica e/ou racial na escola. Fábia e Débora não identificaram o mesmo. É neste ponto que busco tencionar o corte quase vertical que a questão étnico-racial realiza em termos de experiência. Mesmo que o perfil socioeconômico e cultural deste e destas estudantes seja, em certos termos, quase igual, mesmo que em microescala, o debate sobre as identidades negras, preconceito e discriminação étnico-racial acrescenta à pesquisa sociológica uma complexidade importante de ser considerada quando se investiga cenários de constituição, transmissão e incorporação de disposições sociais.

Andressa apresenta notável reflexão sobre sua identidade étnico-racial, e isto está diretamente relacionado com a sua socialização na Comunidade Quilombola. Os laços familiares, de afeto, resistência e ancestralidade são fundamentais na orientação que ela estabelece quanto a essas questões. A escola para ela deveria ser um lugar político, onde se sentisse representada e pudesse, constantemente, aprender para pensar a Comunidade Quilombola. Descreveu que vivenciou em silêncio um conjunto de discriminações e preconceitos quanto à sua cor de pele e cabelo, porém, talvez, para ela, o silenciamento e/ou total desconhecimento das questões quilombolas no currículo e nas práticas escolares assumisse peso semelhante.

Pesquisador - A situações que você vivenciou, estavam relacionadas à identidade quilombola?

Andressa - Não. Sempre... sempre foi mais voltado pra questão de cor, mesmo. Porque... a comunidade quilombola foi reconhecida... reconhecida em 2008. E, até hoje, a escola, que recebe os alunos da comunidade quilombola, não reconhece. Então, como não é falado, as pessoas não levam a sério, e não... as pessoas não... nem sabem o que é ser quilombola. Então, as pessoas, tipo, se falar "é quilombola" é numa questão de brincadeira. Não... não sabem a relação dessa questão "identidade quilombola". Então, sempre foi muito voltado pra questão do meu cabelo, pra questão da minha cor de pele.

José enfrentou muitos insultos racistas referentes à sua cor de pele, principalmente, durante os jogos de futebol na escola, mas não silenciava, rebatendo e requerendo respeito. Ele tem uma reflexão identitária próxima à de Andressa, mas que ainda se encontra em processo de amadurecimento, pois tem descoberto um conjunto de problematizações, na Universidade, em torno das questões étnico-raciais.

$\mathrm{J}$ - Assim, quando eu respondi esse questionário, foi no começo, né. Eu não tinha ainda muito contato com as matérias aqui. Tanto que a UNILAB foi... abriu as portas pra mim, é... pensar de uma forma diferente, né? Até na questão de me identificar. Mas assim, essa questão de eu ter colocado pardo, foi porque eu passei nas... pras cotas, né? Aí, tinha cota lá... a cota de negro (sic), pardo e indígena. 
E... eu fiquei me perguntando, né? "Eu... eu vou me identificar com o quê?". Eu já tive uns... uns... umas treta (sic) lá em [cidade de origem] de preconceito, no colégio... no particular.

$\mathrm{P}$ - Você sofreu preconceito, discriminação?

E - Uhum. No particular, por con... por conta de cor. E... sempre me gerou uma dúvida, né? Porque eu me via mais claro, assim, tudo, mas aí quando eu fui perguntar à minha mãe, a minha mãe disse que eu era pardo, porque o médico tinha colocado pardo nos documentos e tudo. Então, eu me identifiquei como pardo. Mas, hoje, assim, eu já vejo pardo como uma coisa muito criada, muito romantizada, né? Então, eu me vejo como negro, agora.

Bárbara e Mariana vivenciaram contextos semelhantes e reagiram de maneiras próximas. Bárbara contou que enfrentou bullyings por conta de um "problema" de saúde e "brincadeiras" com relação à cor da pele. Nunca contestou e guardou para si. Na entrevista, também se esquivou e não comentou mais do que isso. Mariana teve maior discriminação quanto ao seu cabelo crespo, e sua reação, aos 11 anos, foi alisar para se sentir mais aceita.

$P$ - (...) Você acha que a sua identificação de cor-raça-etnia influenciou ou influencia na sua trajetória de formação escolar?

Bárbara - Eu acho que ela influencia muito porque sempre tem esse negócio de preconceito, racismo, né? Influenciou bastante. Mas a gente tenta não ligar muito pra essas coisas e vai seguindo em frente.

P - Então, na sua escola, você sofreu algum tipo de preconceito, discriminação?

B - Uhum...

Mariana - (...) isso influenciou, porque os meus colegas, na época que eu era mais nova, eles faziam brincadeiras. Em relação à cor da pele, o cabelo, essas coisas. (...) Aconteciam bastante. Mas hoje em dia, eu já não sinto mais. Tipo, eu entrei na faculdade e eu pude, sabe?! Ser quem eu realmente sou. Já na Educação básica, não podia. Tendeu? Me sentida meio... É tanto que eu tinha o cabelo bem "enroladin". Bem "cacheadin" mesmo. E aí, eu acabei alisando, quando eu tinha 11 anos, pra que eu não... não ouvisse mais piadinhas, essas coisas. Pra que as pessoas me aceitassem.

Os casos de Fábia e Débora, embora ambas não identifiquem influência das questões étnico-raciais em suas trajetórias escolares, também não estão isentos das faces do racismo, seja pela tendência ao embranquecimento e/ou miscigenação, pela ausência de debate no currículo e nas práticas pedagógicas que dessem conta de tais questões, ou pelo racismo estrutural-institucional. Uma das falas de Débora é muito ilustrativa destas esferas que resultam na negação de identidades negras, alimentadas por um discurso (mitológico) de "igualdade humana".

D - [Sobre sua forma de autodeclaração para a Política de Cotas] É mais pelo registro. Eu não... Eu me considero todas [as raças]. Porque até... desde a nossa origem, a gente é uma mistura de todos os povos. Até eu fiquei muito em dúvida quando eu fui fazer a inscrição. Eu... "meu deus do céu, vou colocar o quê?". Eu quase que coloco "não identificado". Que tinha lá a opção. Por causa que na... na minha percepção, eu não me encaixo num grupo, porque eu sou a mistura de todos. Por que que eu vou dizer que sou só uma? Mas, pelo registro, tem escrito que é pardo.

(...) 
D - [Sobre a escola ser o lugar onde ela adquiriu esta concepção] É! Exatamente. Exatamente. A gente sempre foi influenciado a não pensar que a gente é uma raça, em si.

(...)

D - [Sobre a questão de gênero] Não. É porque eu me vejo como pessoa. Um ser humano. E não como... mulher ou... qualquer outra coisa.

Uma das falas de Fábia ilustra uma concepção muito enraizada quanto à entrada no ensino superior via Política de Cotas como um marcador de inferioridade de condições de seleção, não com o caráter de Ação Afirmativa que se tem construído. Ao ser indagada, assim como foram os outros, sobre a influência da questão étnico-racial em sua trajetória, imediatamente, ela relaciona com as condições de entrada na Universidade pela ampla concorrência:

F - Acho que não influenciou muita coisa, não. Porque... se eu colocasse na ampla concorrência, né, pela minha nota, eu vi que eu tinha passado também, mas... eu coloquei pela cota mesmo só pra... (risos) só porque eu era parda, né? Mas questão de influenciar...

\section{Para uma outra experiência escolar}

Até aqui, os argumentos que construí estão centrados em preocupações teóricas e metodológicas da pesquisa sociológica. Neste tópico, contudo, gostaria de somar as problematizações de pesquisa à minha interface docente (que não está e nem deve ser separada da interface de pesquisador). Sem desconsiderar as desigualdades de capitais e disposições com as quais os/as estudantes das camadas sociais chegam à escola e como estas disparidades são ressignificadas pela escola (BOURDIEU e PASSERON, 2014) e fundamentais na corrida dos méritos, minha pesquisa também possibilita que se construa um olhar sobre a escola que não é apenas de reprodução desigual, mas de ampliação do horizonte de possibilidades.

Contraditoriamente, ainda que busque tornar minhas considerações menos reprodutivistas, as questões étnico-raciais tornaram possível visualizar outras desigualdades. O racismo na escola se dissemina em muitas práticas, inclusive, à brasileira, de maneira dissimulada. Tentei ilustrá-las de diversas formas: pela invisibilidade e desconhecimento das questões quilombolas, gerando ausência de representatividade e identificação; pelos insultos preconceituosos e discriminadores; a má gerência da intervenção, centrada, na maioria das vezes, em uma interpretação da violência como "brincadeira"; a disseminação de um discurso de igualdade humana, refutado com veemência, há décadas, por muitos/as pesquisadores/as, que enfraquece o debate e reconhecimento das identidades negras; e o fortalecimento de padrões brancos de estética, etc. Por estas razões que me refiro ao conceito de faces interconectas, que vai das relações à estrutura. 
Muitas Leis, Diretrizes, Pareceres, pesquisas, cursos de formação, materiais pedagógicos e variadas formas de intervenção foram e estão sendo produzidas (com protagonismo dos Movimentos Negros) para que isto não se perpetue mais, redimensionando a Educação e a escola em esferas de transformação cidadã e das relações étnico-raciais positivas. Exemplo central disto se dá na construção da Lei 10.639/2003 (BRASIL, 2003), que estabeleceu a obrigatoriedade do ensino de história e cultura afro-brasileiras e africanas - bem como a Lei 11.645/2008, que incluiu a esfera indígena (BRASIL, 2008); da criação, em março de 2003, da Secretaria Especial de Políticas de Promoção da Igualdade Racial (SEPPIR), que assumiu na agenda nacional o compromisso com a criação e estabelecimento de políticas públicas afirmativas, por meio da instituição da Política Nacional de Promoção da Igualdade Racial, e, de modo geral, na lida com as barreiras que impossibilitam o desenvolvimento da população negra; das "Diretrizes Curriculares Nacionais para a Educação das Relações Étnico-Raciais e para o Ensino de História e Cultura Afro-brasileira e Africana" (BRASIL, 2004); na instituição do Estatuto da Igualdade Racial pela Lei 12.288/2010 (BRASIL, 2010); da instituição do Dia Nacional de Zumbi e da Consciência Negra - Lei 12.519/2011 (BRASIL, 2011); e da Lei de Cotas no. 12.711/2012 (BRASIL, 2012).

Seleciono estas ações como forma de problematizar posicionamentos indicativos desta suposta igualdade racial baseada na intrínseca miscigenação brasileira, como aparece na fala de Débora, por exemplo. Este é o grande objetivo em uma sociedade justa e igualitária, porém, não é a realidade em curso. A Educação e a escola assumem posição fundamental porque estruturam espaços para o desenvolvimento dos debates sobre as questões étnico-raciais, socializando conhecimentos científicos e populares que se estendem pela sociedade e são legitimados/reconhecidos por ela. Pensar desta maneira, como professores-pesquisadores que somos, assim como considera a professora Nilma Lino Gomes (2003), perpassa um posicionamento político de que a Educação e a escola precisam se responsabilizar pela luta antirracista. Logo, este sucesso escolar não pode ser considerado apenas nos termos da obtenção de capitais e títulos, mas no desenvolvimento positivo de identidades historicamente negadas.

Com a reestruturação dos currículos, da prática pedagógica e dos materiais didáticos voltados ao aprofundamento e reconhecimento da contribuição africana (e indígena) na edificação da nação brasileira, histórica, social e culturalmente, o processo de afirmação identitária encontra um "(...) pilar para a identidade negra, pois pode servir para desconstruir representações que alienam a pessoa negra de seu próprio corpo e suas raízes étnicoraciais" (FERNANDES e SOUZA, 2016, p. 114). Pensar a escola como espaço de edificação das identidades possibilita que possamos construir um significado de sucesso escolar que 
vai além da obtenção de títulos, de condicionantes de distinção ou de condições de ingresso no mundo do trabalho e em outros espaços com acesso distribuídos desigualmente.

\section{Considerações finais}

O problema que busquei desenvolver aqui tem um forte pano de fundo teórico e metodológico, mas não se afasta da urgência de reconfiguração das práticas na educação escolar formal. Construí isso no primeiro tópico, trazendo um breve debate sobre as questões em torno da relação indivíduo-sociedade. A socialização ultrapassa as barreiras das condições de "classe social" e, visivelmente, alimenta-se de outros marcadores fundamentais como raça e/ou etnia.

Os marcadores étnico-raciais e as questões identitárias não podem ser ignorados. As questões de classe no Brasil, país profundamente condicionado pela sua história (neo)colonial, não podem excluir o debate étnico-racial. Propor este debate ultrapassa o campo propriamente sociológico, que tem se apurado cada vez mais pela crítica e trabalho empírico na constante reestruturação analítica de como tratamos as questões do agente e da estrutura. Trouxe, no espaço possível, apenas uma das contribuições contemporâneas à teoria do habitus. Outras estão a pleno vapor. Porém, a pesquisa em Educação quase nunca se limita à teorização. Foi o que busquei desenvolver nos últimos tópicos.

Propus pensarmos o "sucesso" escolar para além de méritos, capitais e títulos; bem como o "fracasso". A escola cidadã não pode se limitar aos termos do consumo, pois é urgente a transformação social pela chave dos direitos. A entrada desses seis estudantes no ensino superior representa, sociologicamente, um fenômeno muito interessante de ser investigado, mas na lida com os dados empíricos, outros problemas aparecem e que vão além da abordagem analítica. O sucesso nas camadas populares vem acompanhado de uma série de sacrifícios que marcam as trajetórias de quem atravessa as condições de possibilidade. Que a corrida por méritos é desigual nós já sabemos há bastante tempo, mas que ela é também racializada, são poucos que encaram isto. Nesse caso específico, trabalhando também com marcadores étnico-raciais, as trajetórias são atravessadas por outros percalços que se manifestam na experiência, nos sentidos e significados e na formação de identidades.

O desafio é teórico, metodológico, epistemológico e político. Porém, na constituição de um objeto de estudo que se situa entre a seara das relações étnico-raciais, é fundamental que a investigação científica se posicione no campo, para que o conhecimento não se ancore no vazio, mas na urgência da luta antirracista, por exemplo. Isto se faz possível sob as bases de muito rigor científico e engajamento político-social. 


\section{Referências}

BOURDIEU, P. A distinção: crítica social do julgamento. 2. ed. Porto Alegre, RS: Zouk, 2013.

BOURDIEU, P. O senso prático. 3. ed. - Petrópolis, RJ: Vozes, 2011.

BOURDIEU, P. Razões práticas: sobre a teoria da ação. 11. ed. Campinas: Papirus, 2016.

BOURDIEU, P.; PASSERON, J. C. A reprodução: elementos para uma teoria do sistema de ensino. 7. ed. Petrópolis, RJ: Vozes, 2014.

BRASIL, Conselho Nacional de Educação. Parecer CNE/CP 3/2004. Diretrizes curriculares nacionais para a educação das relações étnico-raciais e para o ensino de história e cultura afro-brasileira e africana. Brasília, 2004. Disponível em: <http://portal.mec.gov.br/dmdocuments/cnecp_003.pdf>. Acesso em: 20 out. 2018.

BRASIL. Lei no. 10.639, de 9 de janeiro de 2003. Altera a Lei no 9.394, de 20 de dezembro de 1996, que estabelece as diretrizes e bases da educação nacional, para incluir no currículo oficial da Rede de Ensino a obrigatoriedade da temática "História e Cultura AfroBrasileira". Disponível em: < http://www.planalto.gov.br/ccivil_03/LEIS/2003/L10.639.htm>. Acesso em: 20 out. 2018.

BRASIL. Lei no. 11.645, de 10 de março de 2008. Altera a Lei no 9.394, de 20 de dezembro de 1996, modificada pela Lei no 10.639, de 9 de janeiro de 2003, que estabelece as diretrizes e bases da educação nacional, para incluir no currículo oficial da rede de ensino a obrigatoriedade da temática "História e Cultura Afro-Brasileira e Indígena". Disponível em: < http://www.planalto.gov.br/ccivil_03/_Ato2007-2010/2008/Lei/L11645.htm>. Acesso em: 20 de out. 2018.

BRASIL. Lei no. 12.288, de 20 de julho de 2010: Institui o Estatuto da Igualdade Racial. Disponível em: <http://www.seppir.gov.br/portal-antigo/Lei\%2012.288\%20\%20Estatuto\%20da\%20Igualdade\%20Racial.pdf >. Acesso em: 20 dez. 2018.

BRASIL. Presidência da República. Lei n. 12.519, de 20 de novembro de 2011. Institui o Dia Nacional de Zumbi e da Consciência Negra. Disponível em: < http://www.planalto.gov.br/ccivil_03/_ato2011-2014/2011/lei/12519.htm>. Acesso em: 20 jun. 2018.

BRASIL. Presidência da República. Lei n. 12.711, de 29 de agosto de 2012. Dispõe sobre o ingresso nas universidades federais e nas instituições federais de ensino técnico de nível médio e dá outras providências. Disponível em: <www.planalto.gov.br/ccivil_03/_ato20112014/2012/Lei/L12711.htm>. Acesso em: 20 jun. 2018.

FERNANDES, V. B.; SOUZA, M. C. C. C. Identidade negra: entre liberdade e exclusão. Revista do Instituto de Estudos Brasileiros, n. .063 , abr. 2016 (p. 103-120).

GOMES, N. L. Cultura negra e educação. Revista brasileira de Educação. ํo. 23. Maio/Jun/Jul/Ago, 2003. 
LAHIRE, B. Homem plural: os determinantes da ação. Petrópolis, RJ: Vozes, 2002.

LAHIRE, B. Retratos sociológicos: disposições e variações individuais. Porto Alegre: Artmed, 2004.

VIANA, M. J. B. Longevidade escolar em famílias de camadas populares: algumas condições de possibilidade. 1998. 240 f. Tese (Doutorado em Educação) - Programa de PósGraduação da Faculdade de Educação da Universidade Federal de Minas Gerais, Belo Horizonte, 1998.

WEBER, M. Conceitos básicos de Sociologia. Tradução de Rubens Eduardo Ferreira Frias e Gerard Georges Delaunay. São Paulo: Centauro, 2002. 